\title{
Grijelmo, Álex: Propuesta de acuerdo sobre el lenguaje inclusivo. Barcelona: Taurus, 2019, 293 pp. ISBN: 978843 o619o23
}

El famoso periodista Álex Grijelmo ha vuelto a la carga en su último libro con un tema de polémica y absoluta actualidad, concretamente con lo que él ha llamado una Propuesta de acuerdo sobre el lenguaje inclusivo. El simple hecho de utilizar el concepto «lenguaje inclusivo» (no aceptado por todo el ámbito académico) invita a reflexionar sobre el tono conciliador que el burgalés va a utilizar a lo largo de esta monografía. El escritor de libros que han llegado a ser grandes éxitos como Defensa apasionada del idioma español (1998), La seducción de las palabras (2000) o La información del silencio (2012) ha escrito un ensayo que, como diría la investigadora Escandell-Vidal, huye (o lo intenta) de la trampa de los denominados, en jerga filológica, «temas polarizados» (polirizing topics), que no son otros que aquellos que combaten, como se diría desde la antropología lingüística, por el pensamiento hegemónico en la batalla de las ideologías lingüísticas. Es esta, la cuestión del género y su supuesta bilateralidad (o no) con una categoría óntica de la realidad como el sexo, la que ha tenido el periodista en el punto de mira de sus escritos, asimismo, en la columna donde trabaja en el periódico El País desde hace años, La punta de la lengua, con notas como «No es sexista la lengua, sino su uso» (2/12/2018) o «¿Invisibiliza nuestra lengua a la mujer?» (24/2/2018). Posiblemente del germen de todos aquellos debates en la opinión pública comenzó a surgir el interés por escribir un trabajo que compilase esa y muchas otras opiniones — a menudo enfrentadas-, con y contra las que el autor debate en el propio libro para intentar llegar a un «acuerdo». Esto se corrobora al abrir las páginas de crédito del libro, donde aparece un subtítulo que es invisible en la portada: «Una argumentación documentada para acercar posturas muy diferentes». Pero teniendo este arduo objetivo, ¿lo conseguirá?

El libro, publicado por la editorial Taurus, se compone de 293 páginas y se divide en diez grandes capítulos. El primero, «El origen de los géneros» se trata de un complejo tratado donde se intenta la reconstrucción del origen del problema, acudiendo a las diferentes teorías existentes sobre la asimilación de los géneros gramaticales a los sexos, desde las lenguas que en un inicio utilizaban estas «clases nominales» como cajones de clasificación de otros aspectos a aquellas que lo utilizaban para distinguir, por ejemplo, entre lo vivo y lo muerto, los dioses o los humanos, etc. Para 
Grijelmo, además, la idea de que haya un «oscuro» patriarcado detrás del uso de los morfemas - o y - $a$, o la invisibilización de la que hablan grupos sociales feministas, no tendría mucho sentido cuando acercamos la lupa a diferentes sistemas lingüísticos que pertenecen a sociedades todavía patriarcales y que no disponen de género, de lo que deduce, aludiendo a la «causa falsa» de Aristóteles, que «hechos correlativos no son hechos relativos» (la llamada falacia post hoc ergo propter hoc, «después de esto, luego a consecuencia de esto»). Además, alude a Steven Pinker y asume «el principio de que la correlación no siempre entraña causalidad» (p. 24).

En segundo lugar, se mete de lleno con un tema de actualidad: «Las duplicaciones inclusivas», donde el resalte tipográfico puede ya avisarnos de una ironía o, sencillamente, de una actitud del autor hacia estas duplicaciones, las cuales podría estar poniendo en duda. ¿Son siempre las duplicaciones, los desdoblamientos y las bimembraciones estrategias lingüístico-discursivas «inclusivas»? En este epígrafe, el periodista se adentra en lo que llama «zonas de sombra» para explicar cuándo los desdoblamientos son aceptables y cuándo van contra la propia comunicación, cambiando incluso el sentido de lo que se pretende decir, por lo que el autor menciona que «la duplicación obsesiva puede desatar un efecto opuesto a lo pretendido por sus impulsores. El exceso en los dobletes tiende a resultar contraproducente por agotador y artificial, y se corre el riesgo de que el receptor de los mensajes desconecte de su contenido» (p. 57), lo que olvida, por otro lado, el hecho de que el desdoblamiento lingüístico es un recurso amparado por el sistema y, sobre todo, «apropiado» en según qué discursos o tradiciones discursivas. El hecho de «desdoblar» palabras no tiene por qué conllevar una amenaza contra el sistema, de hecho, como han demostrado todo tipo de investigaciones sociolingüísticas, se hace desde los comienzos del castellano y no ha servido para invocar al cambio lingüístico. En este capítulo se adentra el autor también a hablar de las famosas guías de lenguaje no sexista, a las que volverá en el final del libro para reseñar las propuestas que le parecen acertadas y las que no, así como la artificialidad de la invención del morfema - e como función no marcada del género.

En el capítulo tercero habla del «Lenguaje identitario», lo que entronca muy bien con las investigaciones sobre «ideologías lingüísticas» y el concepto de «tradiciones discursivas» de la Nueva Filología alemana de los últimos tiempos, dado que, como se diría en términos gramscianos, la lucha por la hegemonía siempre va acompañada de un cierto sentido del lenguaje, y cada grupo social tiende a crear, en su lucha, sus propios términos, apropiándose de estos y dándoles nuevos significados o incluso creando otros nuevos. Aquí es donde concede el periodista cierta validez a algunas evoluciones, abriendo la mano a cambios léxico-semánticos como los que se dieron, entre otros muchos, en voces como juez y jueza y otros términos identitarios, que evolucionaron por consenso de la sociedad y por actitudes de los propios hablantes, los cambios «desde abajo» labovianos (pp. 121-140). También nos habla de la polémica del término género y de cómo este se ha utilizado de diferentes formas para acabar hablando de sexo y, ahora, de identidades socioculturales. 
En el cuarto capítulo nos habla de «Mejoras en el Diccionario», donde también explica cómo la Real Academia Española, en su labor de legisladora de la lengua ha cometido una grandiosa labor de adaptación de términos que asimismo evolucionaron primero en la sociedad y en el uso y, como tales, la Academia tuvo que recoger, fruto de luchas sociales diversas. Al mismo tiempo, también arremete contra lo que se ha hecho mal o, simplemente, no se ha hecho, como aquellos ejemplos que aún están «pendientes» $\mathrm{y}$ «no corregidos» (pp. 185-187).

Asimismo, en el quinto, «Problemas de uso sexista» (pp. 195-230), repasa todos aquellos usos sexistas que de hecho se dan a través de la lengua, o sea, en el uso de esta, y que dependen mayormente de parte de los hablantes cambiarlos en su discurrir del habla, o sea, que no tendrían que ser necesariamente problemas, stricto sensu, de lengua, sino, en términos de teoría del lenguaje y, valga la redundancia, de lenguaje.

Tras todos estos capítulos donde el autor «tiende la mano» a considerar algunas propuestas del feminismo sobre el lenguaje, en el capítulo sexto comienza a criticar todo lo que considera innecesario y, además, según dice, inviable, como lo que menciona en «propuestas del feminismo viables aunque, algunas, innecesarias» 0 en el capítulo siete: «propuestas del feminismo difíciles de aplicar». En este último apartado se centra nuevamente en las duplicaciones constantes y en muchas otras recomendaciones ofrecidas en las guías que también analizó Ignacio Bosque en su famoso Informe (2012), donde exponía la «ideología hegemónica» al respecto, la compartida por la Real Academia Española. Así, critica algunas estrategias como la sustitución por adjetivos, la arroba y otros signos, y entra a analizar el problema surgido a través de reividincaciones del colectivo LGTBI+ en torno a los denominados «intersexuales, transexuales y transgénero» y su «inclusión» en la lengua.

Hay una última apuesta de uso de un «femenino genérico» del que dice que «a veces sí», pero obviamente, sin alterar el sistema y la función del género no marcado, que está «sincretizada» dentro del género masculino. Aquí critica los abusos de un supuesto femenino genérico artificial que no respetaría estas normas. En realidad, Grijelmo entronca la tradición estructural y funcionalista del lenguaje, y su visión política al respecto es conservadora — si se prefiere, «purista»—, o sea, de mantenimiento de la norma, pues no se contempla como posible la evolución de determinadas «anomalías». Sin embargo, estas posturas son atacadas desde ideologías alternativas, como las propuestas desde sectores políticos y sociales de las últimas décadas, donde se están utilizando todas estas, incluso rebeldes ante la norma y «acientíficas», como diría José del Valle, para fabricar una «política de la incomodidad».

Finalmente, la parte última del libro le sirve al autor para hacer un «borrador de propuestas de acuerdo sobre lenguaje inclusivo», en donde introduce un repaso de aquellos recursos que fue aprobando a lo largo del libro y, también, de aquellos que le parecen del todo anormativos como para no contemplarlos. En resumen, se trata de un libro de corte funcional y estructural, aunque con cierta permisividad a una visión política alterada. 
196

Con este libro se comprenderá cómo funciona la lengua del ahora y, además, se puede entender cómo pudo haber funcionado en el pasado. Sin embargo, la insuficiencia de este tipo de visionados podría ser criticado pues no abarcaría una visión político-discursiva que permita a los hablantes comprender por qué la norma, a veces, no funciona para todos y, también, por qué a veces esto puede ser el primer germen que provoque un cambio. Así, la lengua, mutante entre la forma y la sustancia, no sería de nadie, sino de todos. Los hablantes, a remolque siempre de sus propias ideas e ideologías, sean estas equivocadas o acertadas, poseen el poder continuo y recursivo de manipular el código que hablan en el momento del discurso, donde podríamos encuadrar la tan ansiada libertad lingüística. Evidentemente, el peso de la historia y la tradición son difíciles de romper, y las propuestas que surgen de diferentes ámbitos no son siempre las más acertadas, pero habría que permanecer atentos, ojo aguileño, a las diferentes fuentes de entrada que el lenguaje posee cuando los hablantes se identifican con este.

Julián Sancha

Universidad de Cádiz

julian.sancha@uca.es

ORCID: oooo-0oo2-9285-1798 